\title{
First record of the genus Spinaethorax Papáč \& Palacios-Vargas, 2016 (Collembola, Neelipleona, Neelidae) in Asia, with a new species from a Vietnamese cave
}

\author{
Clément SCHNEIDER ${ }^{1, *}$ \& Louis DEHARVENG ${ }^{2}$ \\ ${ }^{1}$ Mécanismes Adaptatifs \& Evolution, MECADEV - UMR 7179 - CNRS, MNHN, Dpt Systematics \& \\ Evolution, Muséum national d'Histoire naturelle, CP50 Entomology, 45 rue Buffon, 75005 Paris, France. \\ ${ }^{2}$ Institut de Systématique, Evolution, Biodiversité, ISYEB - UMR 7205 - CNRS, MNHN, UPMC, EPHE, \\ Muséum national d'Histoire naturelle, Sorbonne Universités, 57 rue Cuvier, CP 50, 75005 Paris, France. \\ *Corresponding author: clement.schneider@mnhn.fr \\ 2 Email: dehar.louis@,wanadoo.fr \\ 1 urn:1sid:zoobank.org:author:C0BEC337-0235-4E4B-8EFB-134B3EED1B90 \\ ${ }^{2}$ urn:1sid:zoobank.org:author:D8F5C679-C30C-442C-8621-D3B8EDB17EF7
}

\begin{abstract}
A new species of the genus Spinaethorax Papáč \& Palacios-Vargas, 2016, recently erected for two cave species of Mexico, is described from a Vietnamese cave. It differs from the Mexican species most noticeably by the dorsal chaetotaxy of the head (number and morphology of chaetae), the shape of S-chaetae on the third antennomere, the dorsal chaetotaxy of the abdomen and the chaetotaxy of the dens. The pattern of special $\tau$-chaetae is described for the first time in the genus. The affinities between Spinaethorax and the other genera of Neelipleona are discussed. Spinaethorax is probably closely related to Neelus Folsom, 1896. A table of the differential characters is provided for the three known species of Spinaethorax. Spinaethorax appears to be restricted to caves, but its presence in Vietnam indicates that this genus has a much larger distribution than previously recognized.
\end{abstract}

Keywords. Taxonomy, chaetotaxy, Vietnam, cave fauna, springtail.

Schneider C. \& Deharveng L. 2017. First record of the genus Spinaethorax Papáč \& Palacios-Vargas, 2016 (Collembola, Neelipleona, Neelidae) in Asia, with a new species from a Vietnamese cave. European Journal of Taxonomy 363: 1-20. https://doi.org/10.582/ejt.2017.363

\section{Introduction}

Neelipleona is one of the four orders of Collembola (Massoud 1971, 1976) and contains a single family, Neelidae. The group remained little studied since the discovery of its first representative, Neelus murinus Folsom, 1896. A recent series of morphological and/or molecular contributions has greatly improved the systematics of Neelipleona (Kováč \& Papáč 2010; Schneider et al. 2011, 2016; Papáč \& Kováč 2013; Schneider \& D’Haese 2013; Papáć et al. 2016), especially the genera Neelus Folsom, 1896 and Megalothorax Willem, 1900. Schneider (2017) redescribed the generotypes of Neelus, Neelides Caroli, 1912 and Acanthoneelidus Bretfeld \& Griegel, 2006 and gave an account of the morphological 
knowledge on the entire Neelipleona. This latter work, however, did not include first-hand observations of Zelandothorax Delamare Deboutteville \& Massoud, 1963 or of the recently erected genus Spinaethorax Papáč \& Palacios-Vargas, 2016.

Spinaethorax was created by Papáč \& Palacios-Vargas (2016) to accommodate two cave species of Mexico, Megalothorax spinotricosus Palacios-Vargas \& Sánchez, 1999 and M. tonoius Palacios-Vargas \& Sánchez, 1999. Papáč \& Palacios-Vargas (2016) defined Spinaethorax with the following character set: presence of sensory fields (shared with all genera, except Neelides), sword-like macrochaeta on oral fold (unique), $6+6$ chaetae on basomedian fields of labium (unique), fusion of antennomeres III/ IV (shared with Megalothorax and Zelandothorax), $3+3$ teeth on tenaculum (shared with Neelus and some Megalothorax), $1+1$ neosminthuroid chaetae on sternum of abdomen IV (shared with Neelus and Acanthoneelidus), two chaetae on proximal part of dens (shared with adults of most Neelus species), absence of chaeta E3 on distal part of dens (in adult; shared with Megalothorax, Zelandothorax and Acanthoneelidus) and three chaetae close to the abdominal sensory field (unique).

Collecting carried out during a long-term biodiversity assessment of the Hon Chong karst in South Vietnam led to the discovery of a new species, Spinaethorax adamantis sp. nov. The present paper includes a thorough morphological description of Spinaethorax adamantis sp. nov. and a review of the definition of the genus Spinaethorax. The pattern of $\tau$-chaetae (Schneider et al. 2016) is for the first time described in a species of Spinaethorax. Additional information is given on the morphological affinities of Spinaethorax with the other genera of Neelipleona. Homologies between the genera are suggested for certain morphological characters. A table of the differential characters between the three known species of Spinaethorax is provided.

\section{Material and methods}

\section{Environmental context}

The new species was collected in a small cave of a karstic hill of the Hon Chong karst system in southern Vietnam, close to the border with Cambodia. This karst, an exceptionally rich hot-spot of endemism, is currently under critical threat due to limestone exploitation (Deharveng et al. 2009). The cave Hang Kim Cuong itself is small, $67 \mathrm{~m}$ long (Laumanns 2011), developed at the foot of a rocky hill close to the seaside. The species was obtained by Berlese extraction of thin debris spread irregularly on the floor, but was not found in the small patches of guano present in the cave. This dark, moderately humid cave hosts a remarkable fauna when visited in 2006, including numerous Collembola, some of which are apparently undescribed: Acrocyrtus sp., Ceratophysella sp., Folsomides sp. near F. americanus Denis, 1931, Lepidonella lecongkieti Deharveng \& Bedos, 1995, Megalothorax laevis Denis, 1948, a blind Rambutsinella sp. and several new species of Pronura and Willemia.

\section{Sampling and observations}

The specimens were extracted from the sample with a simple Berlese funnel and stored in $96 \%$ ethanol. They were cleared in lactic acid and mounted on microscope slides in Marc André II medium. They were examined with a Leica DMLB differential phase contrast microscope with magnifications of $\times 250$ to $\times 1000$. Drawings were made with a drawing tube and vectorized with Inkscape. Characters of $S$. spinotricosus and S. tonoius are based on the descriptions of Palacios-Vargas \& Sánchez (1999) and Papáč \& Palacios-Vargas (2016). Measurements were performed with a graduated slide. Values given in $\mu \mathrm{m}$ were measured on a single specimen chosen among the biggest, ratios and proportions are average measures from several relevant specimens. 


\section{Terminology and conventions}

The terminology follows Schneider \& D'Haese (2013), Schneider et al. (2016) and Schneider (2017). Chaetal categories used in the description are defined in Schneider (2017). When referenced, Neelus murinus is always sensu Massoud \& Vannier (1967). The genus names Neelus and Neelides will not be abbreviated for their respective species in order to avoid ambiguity.

\section{Abbreviations and symbols in text}

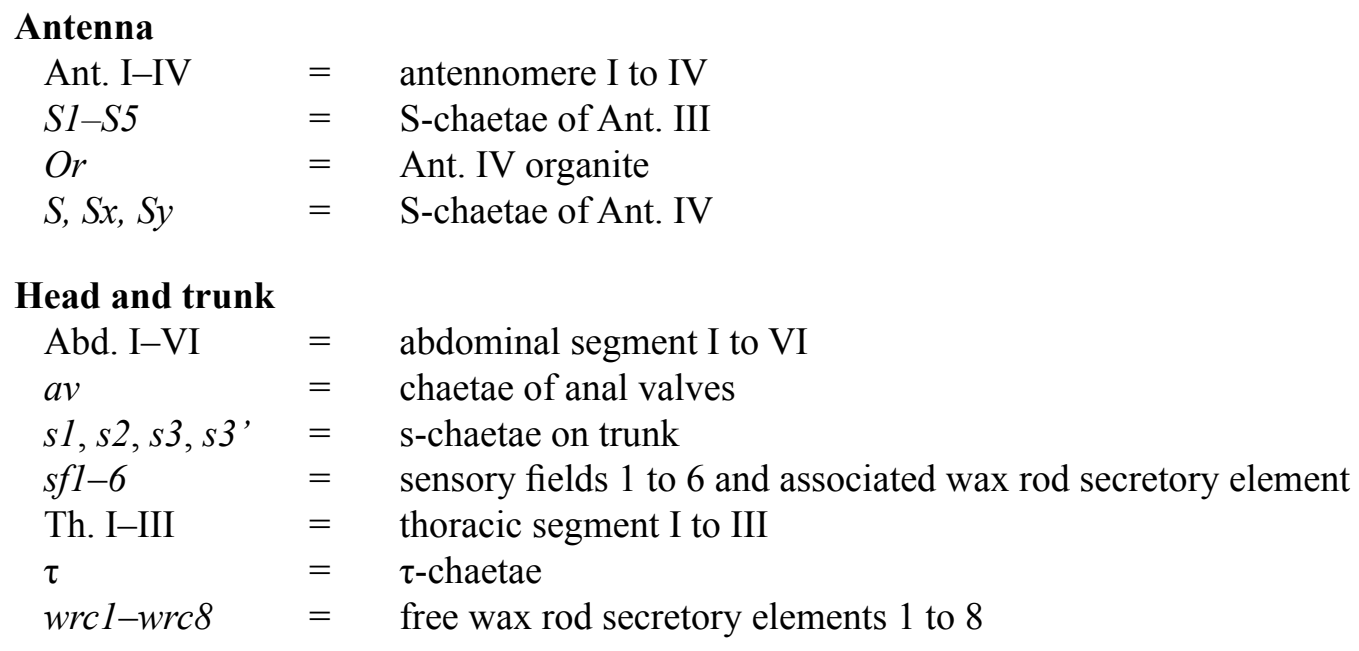

Claw

la, $l p, B p \quad=\quad$ auxiliary lamellae of unguis

\section{Institutional abbreviations}

HCMU = Ho Chi Minh City National University, Department of Biology, University of Natural Sciences, Ho Chi Minh City, Vietnam

MNHN = Muséum national d'Histoire naturelle, Paris, France

\section{Results}

Class Collembola Lubbock, 1873

Order Neelipleona Massoud, 1971

Family Neelidae Folsom, 1896

Genus Spinaethorax Papáč \& Palacios-Vargas, 2016

Figs $1-8,9 \mathrm{~A}$, D; Table 1

\section{Revised diagnosis}

Eyes and post-antennal organ absent. Secondary granulation made of fine grains; dermastra missing; integumentary channels absent. Anterior process of labrum absent or very weak. Ant. III and IV fused; S-chaeta $S 1$ short and wide; S-chaeta $S 5$ present; two apical sensory rod-like chaetae $(a, s a)$. Basomedian fields of labium with $4+4$ chaetae; basolateral fields of labium with $3+3$ chaetae. Oral fold with enlarged lateral chaeta. Sensory fields well-developed with swollen inner chaetae; $s f 6$ with three guard chaetae. Trunk with $4+4$ s-chaetae $\left(s 1, s 2, s 3, s 3^{\prime}\right)$. Abd. IV sternum with $1+1$ neosminthuroid chaetae. Distal articular process of manubrium with convex tip. Dens without median articular process. Unguis with basal narrowing; with well developed lamella $B p$; lamella la missing on unguis II. Tenaculum with $3+3$ teeth. 
Keys or tables for determination of the genera of Neelidae are available in Papáč \& Palacios-Vargas (2016) and Schneider (2017).

Spinaethorax adamantis sp. nov. urn:1sid:zoobank.org:act:B0F131AB-279A-4890-A33B-ED70D437828D

Figs 1-8, 9A, D; Table 1

\section{Diagnosis}

Postero-dorsal area of head with $12+12$ chaetae including $5+5$ lanceolate chaetae. Antero-dorsal area of head with two unpaired chaetae. Ant. III with 14 chaetae; S-chaetae $S 2, S 3, S 4$ long and tubular. Dorsal area of Th. II with $4+4$ thickened or lanceolate chaetae. Abd. I-V terga without spine-like microchaetae. Abd. VI tergum with thickened chaetae. Subcoxa 2 III and coxa III with thickened chaetae. Dens proximal part with one strong chaeta.

\section{Differential diagnosis}

Spinaethorax adamantis sp. nov. differs from S. spinotricosus and S. tonoius in several characters, summarized in Table 1. Most notably, S. adamantis sp. nov. has only one proximal chaeta on dens (instead of two in the other species), long and tubular S-chaetae $S 2, S 3$ on Ant. III (vs short in the other species) and a long and tubular S-chaetae $S 4$ (vs short and globular in the other species). S. adamantis sp. nov. and S. tonoius differ most strikingly from S. spinotricosus by the absence of the numerous spinelike microchaetae (reduced number of ordinary chaetae instead).

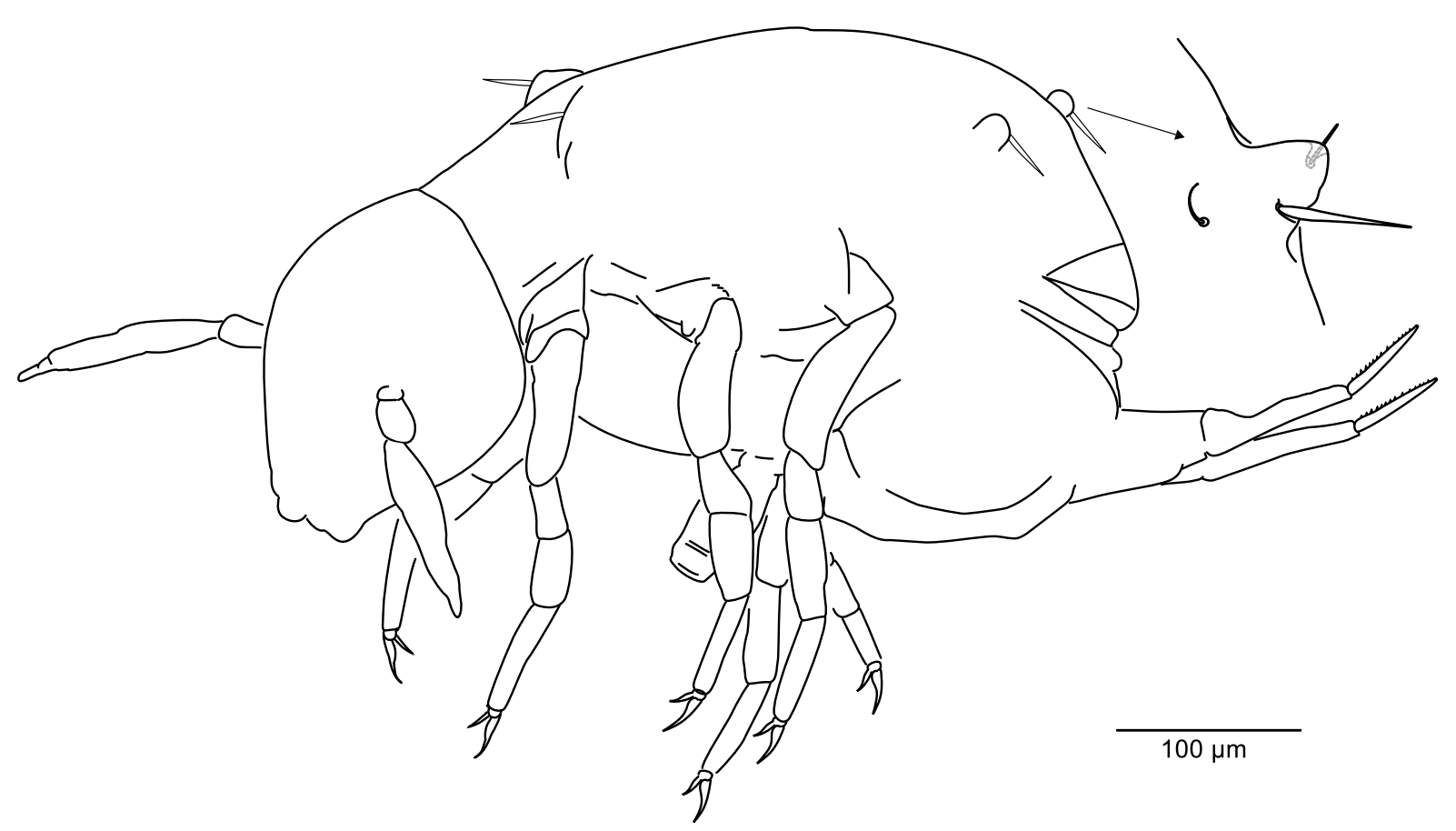

Fig. 1. Spinaethorax adamantis sp. nov., habitus, with enlargement of the protuberance bearing wax rod secretory element of $s f 6$. 


\section{Etymology}

The name is derived from the Latin adamas (diamond) and is inspired by the local name for the cave Hang Kim Cuong, "Diamond Cave", in which the new species was collected. The name emphasizes that one of its richnesses lies in the biodiversity instead of actual diamonds.

\section{Material examined}

\section{Holotype}

VIETNAM: $\widehat{\partial}$, on slide (MNHN-EA040281), Kien Giang Province, Kien Luong, Hon Chong karst, Nui Hon Chong hill (also called Nui Chua Hang), Hang Kim Cuong (Diamond Cave), 28 Nov. 2006, $\mathrm{X}=104.639784 \mathrm{E}, \mathrm{Y}=10.137582 \mathrm{~N}$, elevation about $15 \mathrm{~m}$, extracted with Berlese funnel from soil in the dark zone of the cave, L. Deharveng and A. Bedos leg. (sample Vn06-088) (MNHN).

\section{Paratypes}

VIETNAM: 3 qq, 1 o, 1 specimen of unknown sex on 3 slides, same data as the holotype, three paratypes deposited in the collection of the MNHN (France), two paratypes in the collection of the HCMU (Vietnam).

\section{Description}

SizE. Length from labrum to anus of largest specimen $\sim 550 \mu \mathrm{m}$.

Pigmentation. Whitish in alcohol.

GeNERAL SHAPE AND BODY SEGMENTATION (Fig. 1). Orthognathous. Antennae directed laterally with a slight curve toward the anterior direction, slender. Ant. III and IV fused. Total length of antenna $\sim 148 \mu \mathrm{m}$; max width (Ant. III) $\sim 18 \mu \mathrm{m}$; ratio width : length $\sim 0.12$; relation of length of Ant. I : Ant. II : Ant. III : Ant. IV $0.15: 0.5: 1: 1$. Point of insertion of head on Th. I aligned with antero-posterior axis of the head. Diameter of Th. I slightly reduced without steep curve between Th. I-head and Th. I-II. Th. I in one part, neck missing. Th. I-head articulary folds not observed. Terga from Th. II to Abd. V fused. Posterior granule $T$ of the dorso-median line missing, replaced by a small unpaired patch devoid of secondary granules (T, Fig. 4A). Wax rod secretory elements of $s f 3$ (dorsal area of Th. II) and of $s f 6$ (dorsal area of abdomen) standing on strong, protruding processes (Fig. 1). Precoxal area of Th. II and III without clear anterior lobe. Each coxa long and bent. On leg I and II length of coxa $>$ tibiotarsus $>$ femur $>$ trochanter. On leg III length of coxa $>$ tibiotarsus $\sim$ femur $>$ trochanter. Abd. VI sternum clearly separated posteriorly from Abd. VI tergum by large anal aperture, separated anteriorly from Abd. V sternum by a steep curve, Abd. VI sternum distinct laterally from the great abdomen terga by the absence of secondary granulation. Abd. IV sternum enlarged, creating a large ventro-posterior side bearing the furca. Abd. I-III sterna reduced with tenaculum close to ventral tube. Manubrium/dens articular processes: manubrium with weak process bearing hardened peg with convex tip that connects to concave tip of strong, projecting process of dens (Fig. 6C). Dens proximal part wider than the distal part with a steep curve between the two. No suture line or articular process between proximal and distal part of dens (Fig. 6D). Relation of length of manubrium : dens proximal part : dens distal part : mucro $\sim 0.90: 0.32: 1: 0.82$.

INTEGUMENT. With a simple secondary granulation made of fine granules. Secondary granulation present on posterior part of Th. II to Abd. V terga (Fig. 4A), absent on head, antennae, Abd. VI tergum, furca, legs, thoracic and abdominal sterna. Dermastra missing. Integumentary channels missing.

ChAetAe. Seven morphological variations of chaetae on head and trunk: (i) ordinary chaetae; (ii) s-chaetae, short and swollen chaetae $\left(s 1-s 3, s 3^{\prime}\right)$ found on trunk; (iii) $\tau$-chaetae, long and flexible chaetae shaped as trichobothria with basal ring implanted in a small depression of the integument and weakly contrasted in light microscopy, found on trunk ( $30-35 \mu \mathrm{m}$, Fig. 4B); (iv) wax rod secretory crypts associated with 


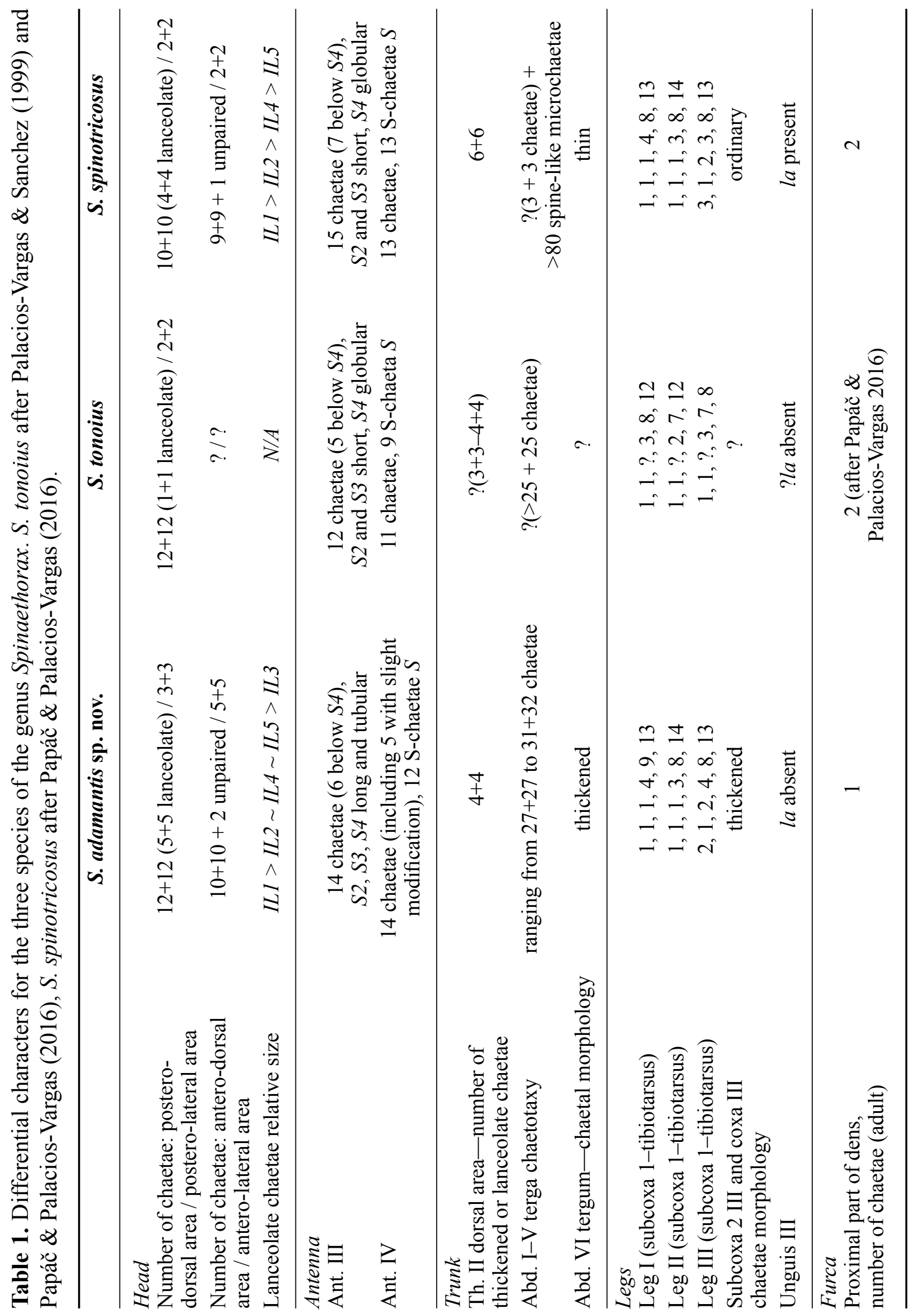


A
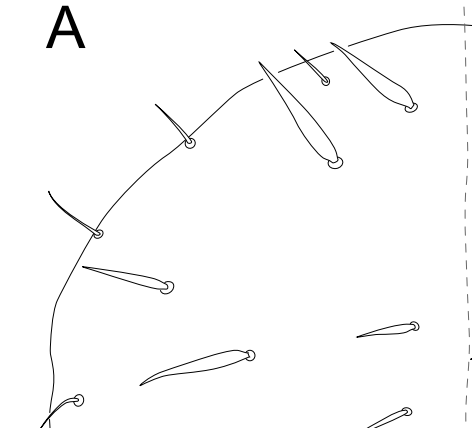

个
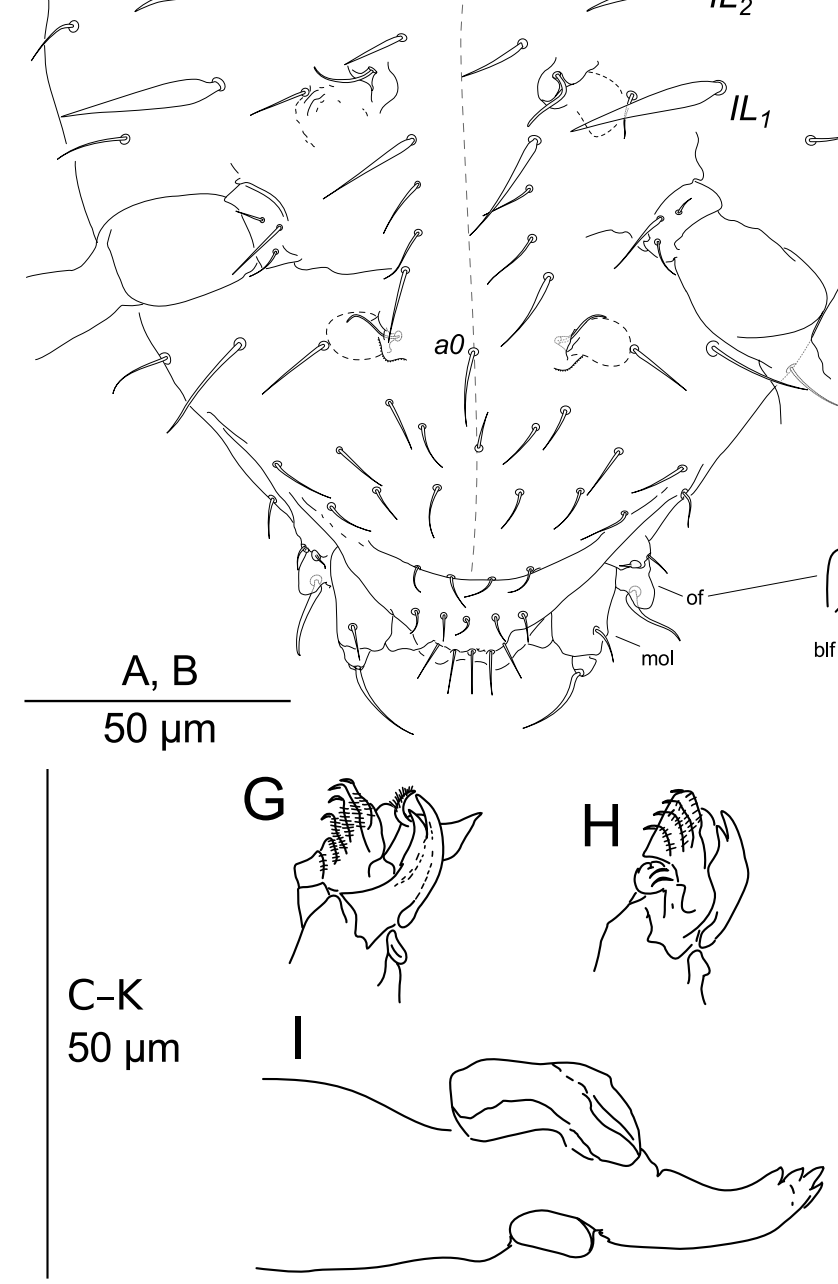

B

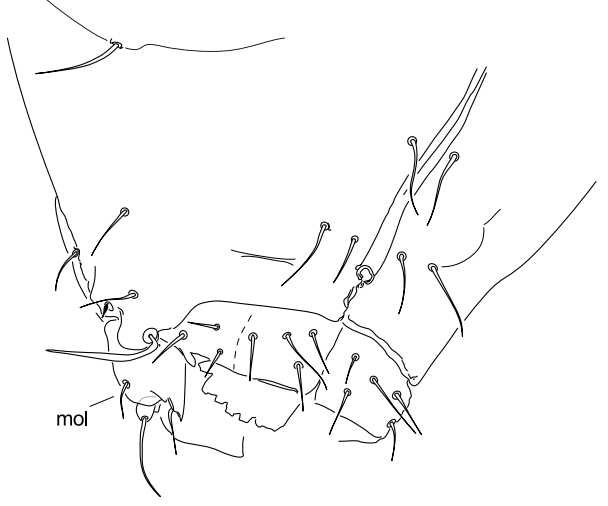

$\mathrm{D}$

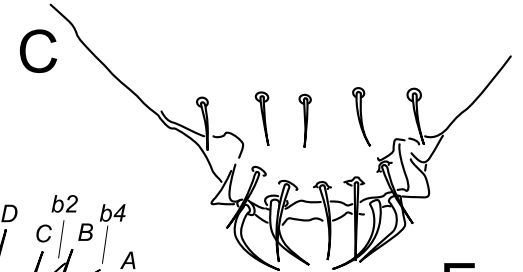

mol
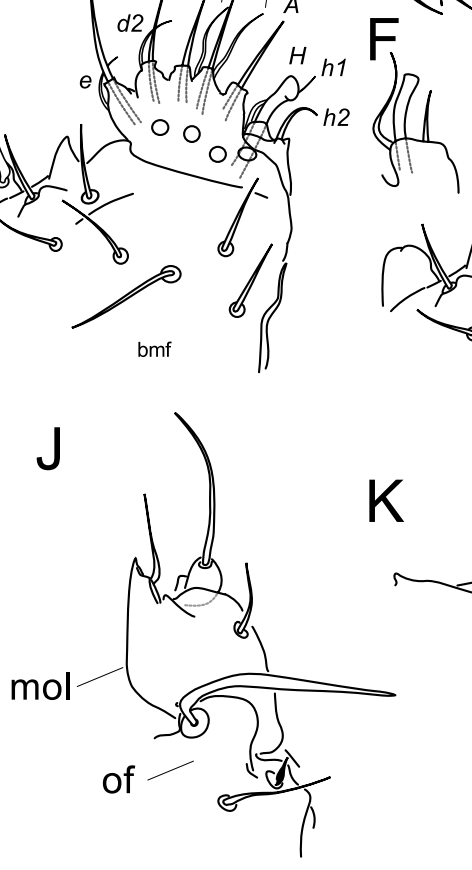

$\mathrm{E}$
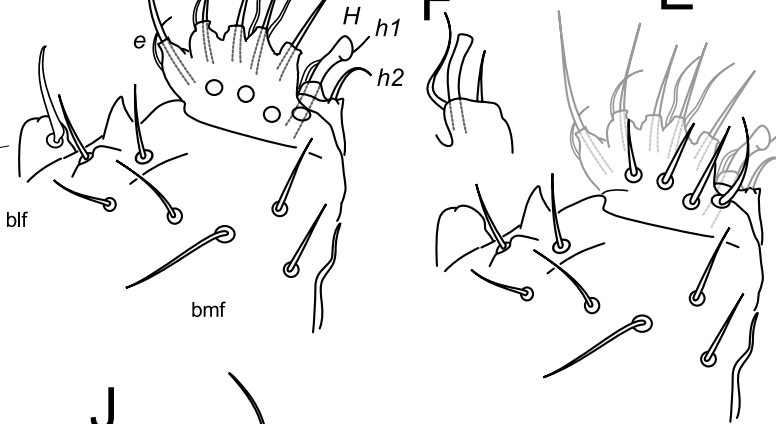

K

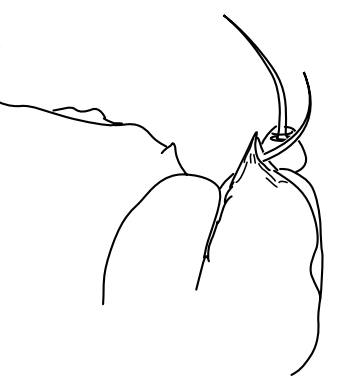

Fig. 2. Spinaethorax adamantis sp. nov. A-B. Chaetotaxy of the head. A. Dorsal side. B. Ventral side, anterior part. C. Labrum dorsal side. D-F. Labium. D. Focus on papillate chaetae of the palp. E. Focus on chaetae in proximal field. F. focus on papilla $H$. G-H. Maxilla, different views. I. Left mandible. $\mathbf{J}-\mathbf{K}$. Maxilla outer lobe. J. Lateral side. K. Ventral side. Abbreviations: blf = basolateral field of labium; $\mathrm{bmf}=$ basomedian field of labium; $\mathrm{mol}=$ maxilla outer lobe; of $=$ oral fold. Labial palp lettering after Fjellberg (1999). 
a sensory field; (v) free wax rod secretory crypts (wrcl-8); (vi) inner swollen chaetae of sensory fields; (vii) neosminthuroid chaetae. Ordinary chaetae size ranging from microchaetae [1-6 $\mu \mathrm{m}]$, mesochaetae [7-15 $\mu \mathrm{m}]$ to macrochaetae [16 $\mu \mathrm{m}-42 \mu \mathrm{m}]$. Ordinary chaetae morphology ranging from simple to lanceolate; including spectacular lanceolate macrochaetae on head and thorax (Figs 2A, 4A).

SENSORY FIELDS AND WAX RODS. Six pairs of sensory fields (sfl-6) on head and trunk, each field associated with a wax rod secretory crypt (Figs $2 \mathrm{~A}, 4 \mathrm{~A}$ ). On head: $s f 1$ preantennal without special inner chaeta (Fig. 2A); $s f 2$ postantennal without special inner chaeta (Fig. 2A). On trunk: $s f 3$ dorsally on Th. II with three short candlelight-shaped inner chaetae (Fig. 4A); sf4 in precoxal area of Th. II with two short candlelight-shaped inner chaetae (Fig. 4A); $s f 5$ in precoxal area of Th. III and $s f 6$ dorsally on posterior part of abdomen, each with a short candlelight-shaped inner chaeta (Fig. 4A). sf6 well developed (Fig. 4A). Eight pairs of free wax rod secretory crypts (seven in Th. III tergum area, eight in abdominal terga area) (Fig. 4A). Edges of $s f 5$ and $w r c 5$ separate, $w r c 8$ in antero-ventral position and close to $s f 6$ (Figs 4A, 9D). Tertiary wax rod secretory elements apparently missing.

LABRUM. Labrum without clearly differentiated anterior process, a-row of chaetae very close to labral ridge (Fig. 2C). a-row consisting of two pairs of smooth, slightly thickened and strongly curved mesochaetae $(a 1, a 2)$. $\mathrm{m}$ - and p-rows of chaetae each with five mesochaetae (Fig. 2C). Labral ridge without apical hairs or spines (Fig. 2C).

LABIUM. Basomedian fields with $4+4$ mesochaetae (Fig. 2B, D-E). Basolateral fields with $3+3$ mesochaetae (lateral chaetae on weak tubercles) and with small antero-lateral integumentary processes (Fig. 2B, D-E). Proximal field with four mesochaetae (Fig. 2E). Palp with six papillate chaetae and six guard hairs as $(H, h 1, h 2),(A),(B),(b 2, b 4),(C),(D, d 2),(E, e)$ (lettering sensu Fjellberg 1999). Hypostomal papilla $(H)$ with a strong, apically enlarged chaeta, other papillae with acuminate, straight or slightly curved chaetae (Fig. 2D, F).

OTHER MOUTHPARTS. Oral fold with two chaetae and a microspine, ventral chaeta enlarged and strongly curved near the base, lateral chaeta of ordinary morphology (Fig. 2A-B, J). Maxilla outer lobe with sub-basal mesochaeta and apical papilla bearing a mesochaeta (Fig. 2J-K), apical papilla without annex hair (Fig. 2J-K), sublobal plate with strong hair (Fig. 2J-K). Left and right mandibles each with four apical, rounded teeth (Fig. 2I). Maxilla with at least four cilliated lamellae, capitulum with two hooked teeth (Fig. 2G-H).

Head chaetotaxy. Postero-dorsal area with $12+12$ chaetae: $5+5$ macrochaetae, $6+6$ mesochaetae in f.p-pa.a-rows, $1+1$ mesochaetae on the border of $s f 2$ (Figs 2A, 7A). Postero-lateral area with $3+3$ mesochaetae (Figs 2A, 7A). Antero-dorsal area with 10+10 mesochaetae and two unpaired mesochaetae (Figs 2A, 7A). Antero-lateral area with $1+1$ macrochaetae and $4+4$ mesochaetae (Figs 2A, 7A). Ventral area with $3+3$ post-labial mesochaetae (Figs 2B, 7B).

Antennal chaetotaxy. Ant. I with three dorsal chaetae (Fig. 3A). Ant. II with six chaetae in two whorls, one in basal whorl, five in apical whorl (Fig. 3A-B). Ant. III with 14 chaetae in 4 rough whorls distributed as 1, 2, 4, 7 (Fig. 3A-B), of varied morphology, ranging from thin ordinary chaetae to "S-chaetae S-like"; five S-chaetae (S1-S5). S1 as a plump, stalked chaeta, possibly with four folds (Fig. 3A, D), S2-S4 long and tubular with blunt apex, S5 short with pointed apex (Fig. 3A-B). Ant. IV with 14 chaetae, 14 S-chaetae $(12 S, S x, S y)$, one organite $(O r)$ and two apical and subapical sensory rods $(a, s a)$ (Fig. 3A-C). Five chaetae slightly departing from the ordinary morphology in a large and contrasted basal ring, a subtly more tubular aspect (vs conical aspect) and outward curving (vs inward curving) (Fig. 3A-B). S-chaetae $S$ scarcely differentiated from ordinary macrochaetae, with apex finely rounded. $S y$ thick and tubular with round apex, $S x$ as long as $S y$ but slender with round apex (Fig. 3A, C). 
Organite apparently bifid with two thin arms apically converging, one perceptibly larger than the other (Fig. 3A, C). Ornamentation of S-chaetae not seen with light microscopy.

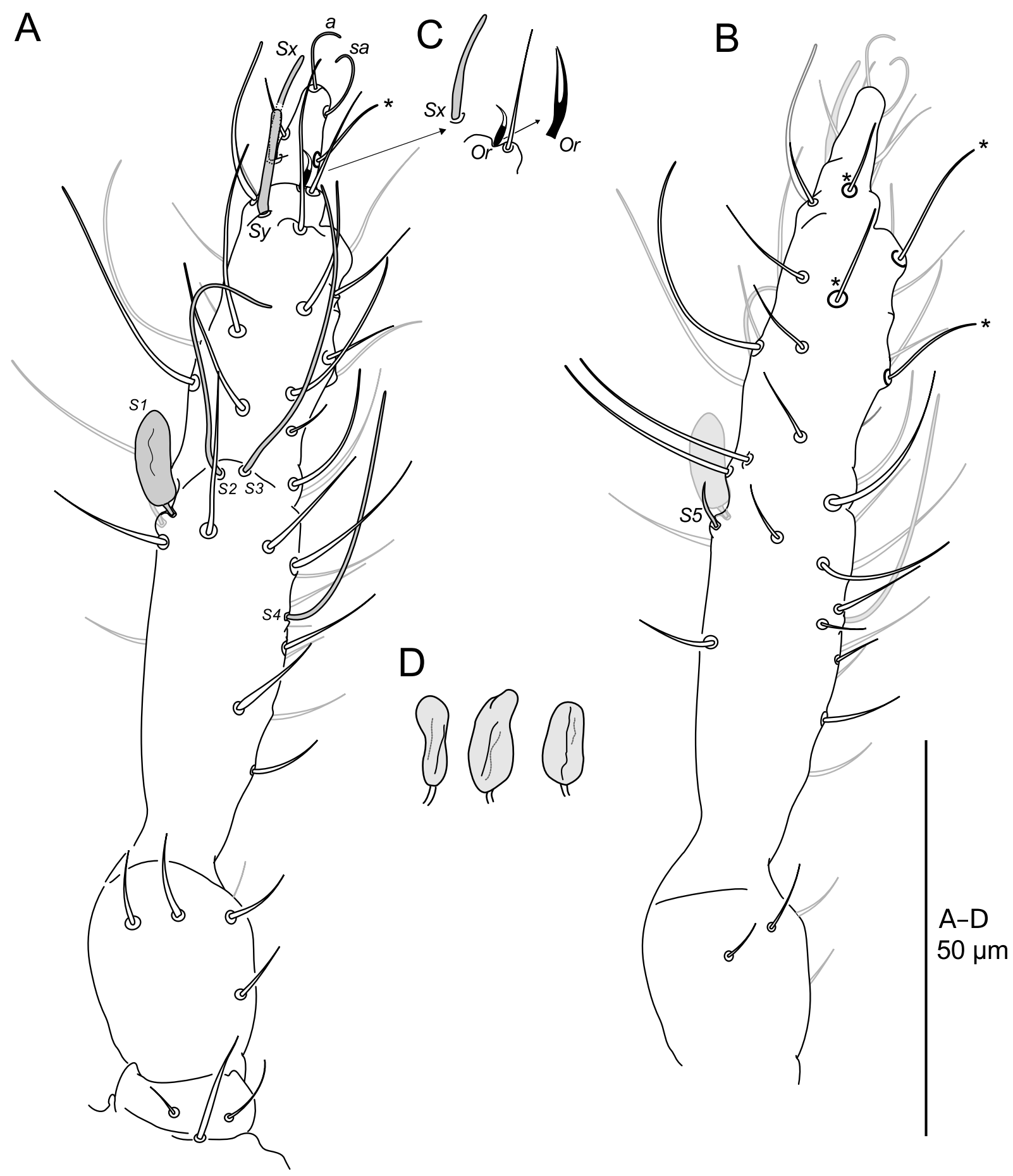

Fig. 3. Spinaethorax adamantis sp. nov. A-D. Chaetotaxy of the antenna. A. Dorsal side. B. Ventral side. C. Focus on S-chaeta $S x$ and Organite $O r$ with enlargement of the latter. D. S-chaeta $S 1$, different aspects. Asterisks indicate modified chaetae. Chaetae implanted on the other side represented with gray stroke. 
Th. II-Abd. V terga Chaetotaxy. Th. II-Abd. V terga with a minimum of $52+52$ chaetae, $12+12$ $\tau$-chaetae, $4+4$ s-chaetae $(s 1, s 2, s 3, s 3$ ') and $8+8$ wrc (Figs 4A, 7C). Dorso-lateral areas of Th. II with $5+5$ macrochaetae, $4+4$ mesochaetae and $2+2 \tau$-chaetae (Figs $4 \mathrm{~A}, 7 \mathrm{C}$ ), lengths of the 5 macro- and 4 mesochaetae 13-40 $\mu \mathrm{m}: a 4(13 \mu \mathrm{m})<a 1, p 1, p 4<a 2<p 3<a 5, p 2<a 3(40 \mu \mathrm{m}) ; a 2, a 3, a 5$ and $p 2$ thickened. Precoxal areas of Th. II with $5+5$ macrochaetae, $1+1$ s-chaetae s1 and $1+1 \tau$-chaetae (Figs 4A, 7C); lengths of chaetae $a 8, a 9(22 \mu \mathrm{m})<p 7<p 8<a 7(42 \mu \mathrm{m}) ; a 7, p 7$ and $p 8$ thickened. Dorso-lateral areas of Th. III-anterior abdomen with $16+16$ chaetae, $2+2$ s-chaetae $\left(s 3, s 3^{\prime}\right) 5+5$ wrc $(w r c 1-4$, wrc 7$)$ and $7+7 \tau$-chaetae (Figs $4 \mathrm{~A}, 7 \mathrm{C}$ ); chaetae consisting of $1+1$ macrochaetae $(p 7,35 \mu \mathrm{m})$, the others as mesochaetae; $p 2$ and $p 3$ slightly thickened, $p 7$ strongly thickened; wrc 3 thickened. Precoxal areas of Th. III with $3+3$ chaetae, $2+2$ wrc $(w r c 5-6)$ and $1+1 \tau$-chaetae (Figs 4A, 7C); chaetae including $2+2$ thickened macrochaetae ( $a 8-45 \mu \mathrm{m}, p 8-22 \mu \mathrm{m}) ;$ wrc 5 thickened. Posterior area of the abdomen (until Abd. $\mathrm{V}$ included) with chaetae in variable numbers and tendency to asymmetrical distribution (range seen $19+19$ to $23+24$ chaetae), $1+1$ s-chaetae $(s 2)$ and $1+1 \operatorname{wrc}(\operatorname{wrc} 8)($ Figs $4 \mathrm{~A}, 7 \mathrm{C})$; chaetae including $8+8$ macrochaetae $(17-34 \mu \mathrm{m})$ and $13+13$ mesochaetae. $s 1$ tubular, $s 2$ bean-shaped (Fig. 4C), s3, s3' light bulb-shaped (Fig. 4A).

Leg ChaEtotaxy. Leg I (Fig. 5A) subcoxa 1, subcoxa 2 and coxa each with one chaeta; trochanter with four chaetae ( 2 proximal, 2 distal); femur with nine chaetae; tibiotarsus with 13 chaetae in five rough whorls distributed as 2, 2, 1,3,5; one of the apical anterior chaetae slightly different (weak contrast, thin and with subtly blunt apex). Leg II (Fig. 5B) subcoxa 1, subcoxa 2 and coxa each with one chaeta; trochanter with three chaetae; femur with eight chaetae; tibiotarsus with 14 chaetae in four rough whorls distributed as 3, 4, 3, 4. Leg III (Fig. 5C) subcoxa 1 with two chaetae; subcoxa 2 with one chaeta; coxa with two chaetae in proximal position; trochanter with four chaetae; femur with 8 chaetae; tibiotarsus with 13 chaetae in four rough whorls distributed as 2, 4, 3, 4. Each pretarsus with two microchaetae, one

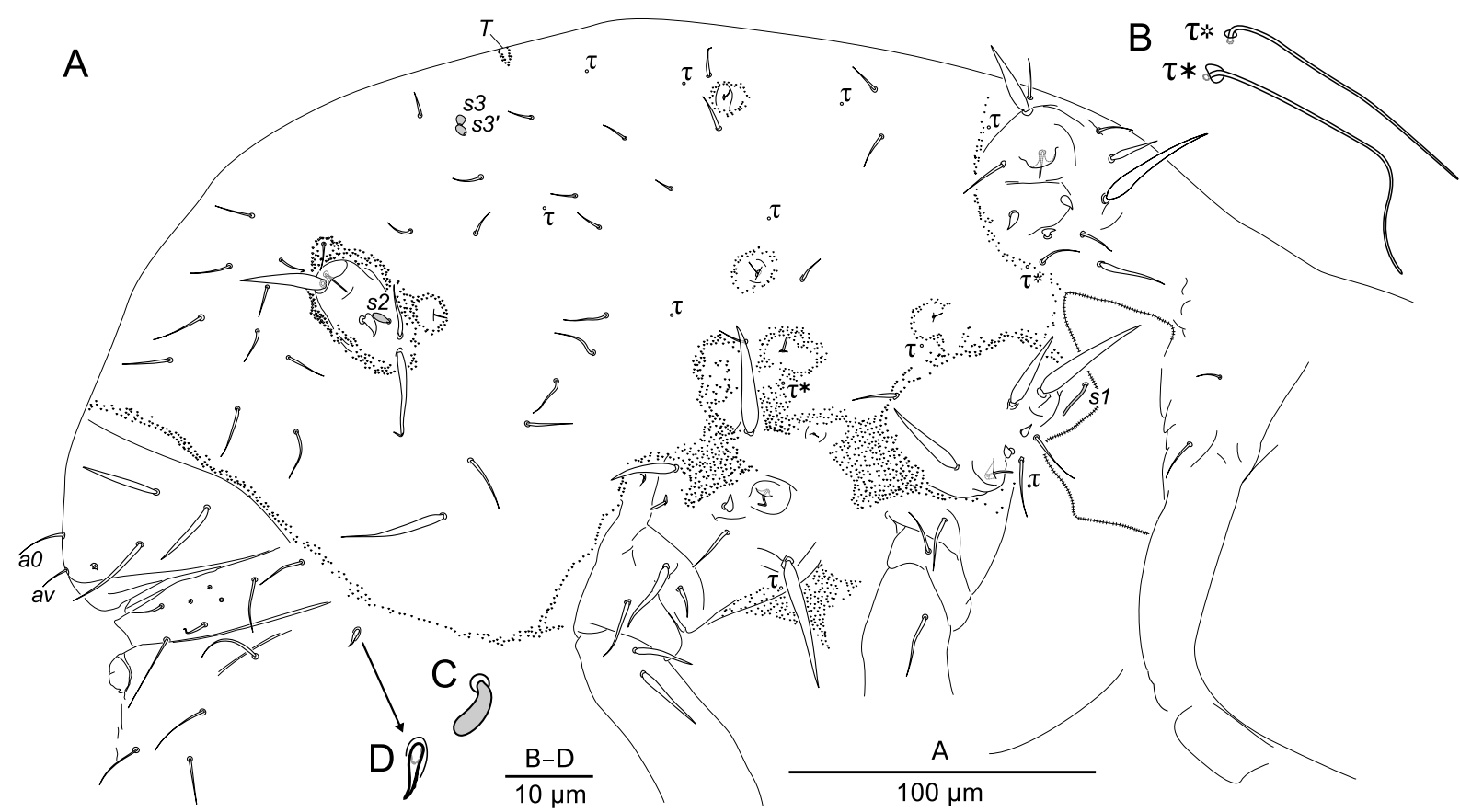

Fig. 4. Spinaethorax adamantis sp. nov. A. Chaetotaxy of the trunk. B. Focus on the $\tau$-chaetae (asterisks link $\tau$-chaetae in A and B). C. Focus on s-chaeta $s 2$. D. Focus on the neosminthuroid chaeta. Secondary granulation of Th.II-Abd.V terga partially shown (anterior, ventral and posterior limits, also limits near sensory fields and $w r(-8)$. 


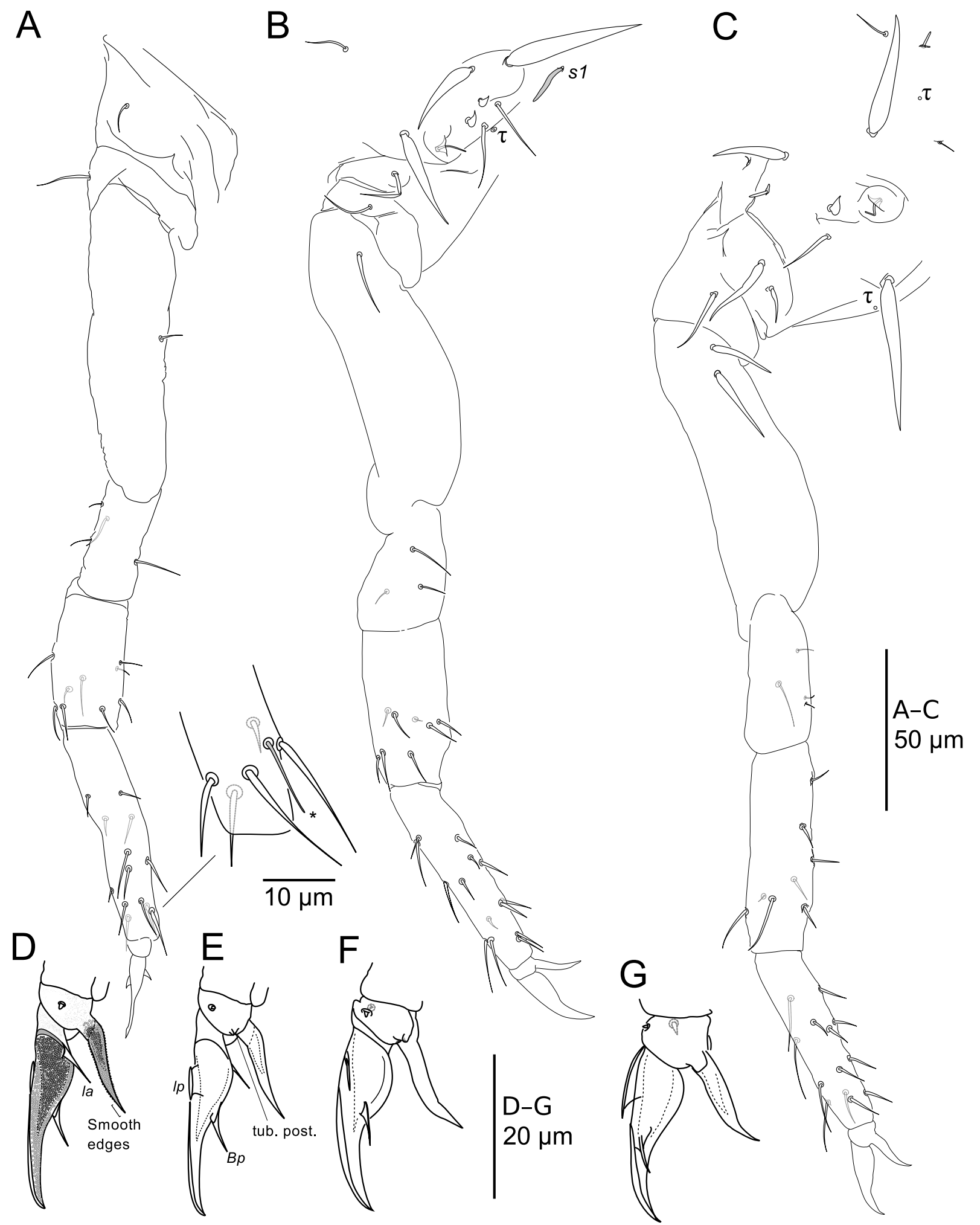

Fig. 5. Spinaethorax adamantis sp. nov. A-C. Chaetotaxy of legs. A. Leg I with focus on apical chaetae of tibiotarsus, asterisk indicates a special chaeta. B. Leg II (also with $s f 4$ on Th. II precoxal area). C. Leg III (also with $s f 5$ on Th. III precoxal area). D-G. Morphology of claws. D. Claw I posterior side. E. Claw I anterior side. F. Claw II posterior side. G. Claw III posterior side. 
on anterior side and one on posterior side, the anterior chaeta larger than the posterior chaeta (Fig. 5D$\mathrm{G})$.

Claws. Ratio unguis length: pretarsus width on leg I-III, respectively $\sim 3.5,3.3,2.8$. Ratio of unguiculus: unguis for claw I, II, III $\sim 0.5,0.55,0.45$ (Fig. 5D-G). Unguis with basal narrowing (Fig. 5D-G). On claw I lamella la moved in anterior position, shaped as a thin spine (Fig. 5D); on claw II and III lamella la missing (Fig. 5F, G). On each claw lamellae $l p$ and $B p$ well developed (Fig. 5D-G).

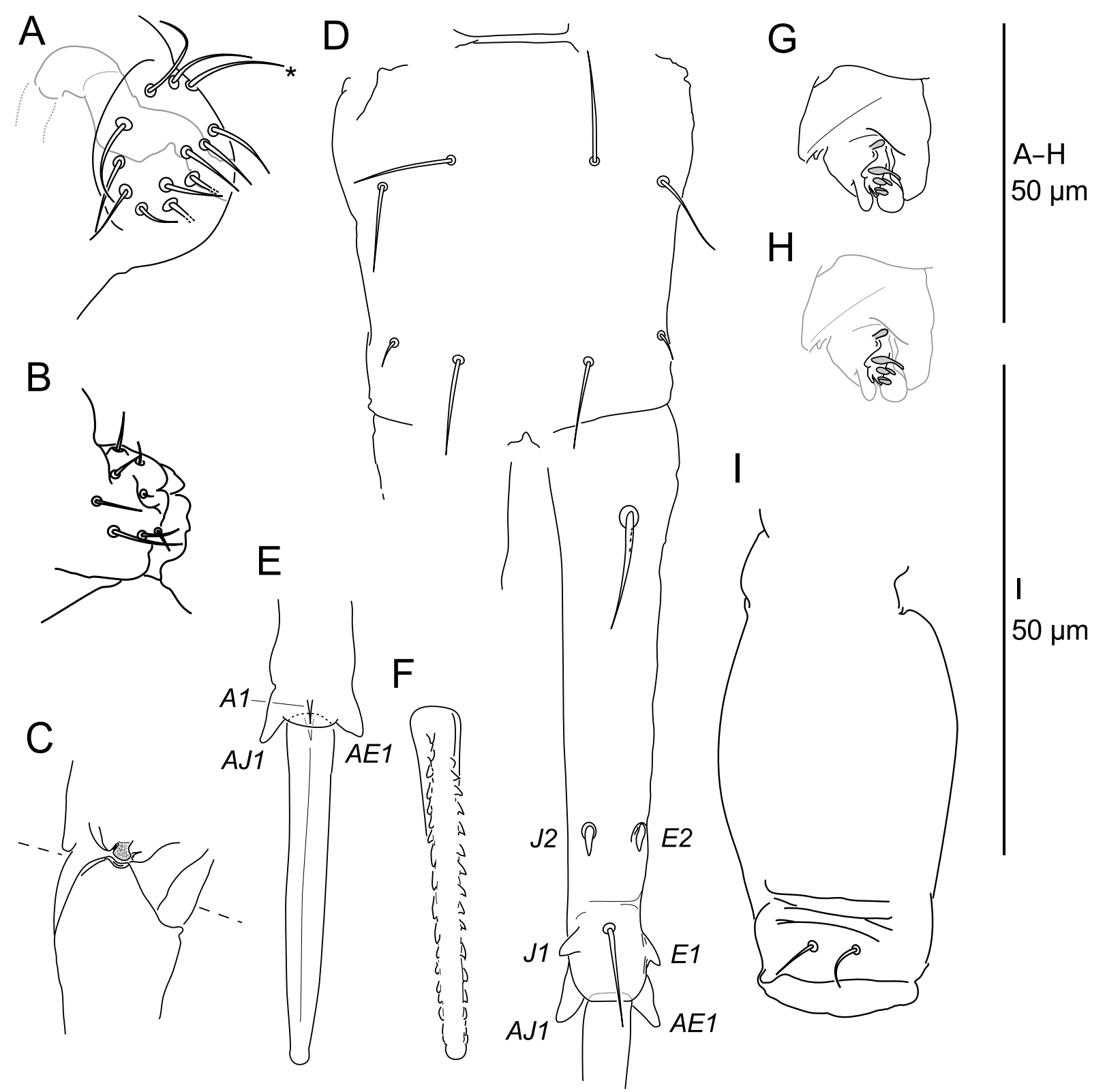

Fig. 6. Spinaethorax adamantis sp. nov. A-B. Male sexual apparatus. A. Male genital plate (asterisk indicates a chaeta not seen on other side, possibly unpaired). B. Immature male genital plate. C. Manubrium/ dens anterior articular process. D. Chaetotaxy of manubrium and dens posterior side. E. Distal part of dens and mucro anterior side. F. Mucro posterior side. G-H. Tenaculum. H. Focused on apical teeth and basal process. I. Ventral tube lateral side. 
On unguiculus basal tubercle reduced to very small posterior integumentary process, lamella of the unguiculus with slender, conical aspect, without perceptible crests and with smooth edges reduced to apical part (Fig. 5D-G). Ratio of unguis length : tibiotarsus length on leg I-III $\sim 0.38,0.4,0.4$.

ABD. VI AND GENITAL CHAETOTAXY. Abd. VI tergum with $3+3$ macrochaetae, two unpaired mesochaetae $(a 0, a v)$ and $1+1$ microchaetae ( $\mu . a v)$ (Figs 4A, 7C). Abd. VI sternum with $5+5$ chaetae (including $a v)$, $2+2$ microchaetae $\mu . a v$ and $1+1$ small basal rings without visible chaetal element (Figs 4A, 7C). No clear delimitation between anal valves and rest of Abd. VI tergum and sternum. Male genital plate either with $6+6$ circumgenital chaetae or $5+5$ and one unpaired circumgenital chaetae and $7+7$ eugenital chaetae (Fig. 6A). Immature male observed with $8+8$ or $9+9$ chaetae or microspines (Fig. 6B). Female genital plate not observed.

ABD. IV STERNUm AND FURCA. Abd. IV sternum with $4+4$ chaetae and $1+1$ neosminthuroid chaetae (Fig. 4A). Neosminthuroid chaetae flame-shaped, with very minute teeth (Fig. 4A, D). Manubrium with $4+4$ chaetae (Fig. 6D). Posterior side of dens with a strong proximal chaeta with minute external teeth, two subdistal conical spines with basal ring, a distal chaeta and two lobe-like distal spines without basal ring; anterior side distally with small acute spine and two lobes (blunt spines) without basal ring (Fig. 6D-E). Mucro with thin lamellae, posterior lamellae serrate (15-17 teeth), apex rounded (Fig. 6F-G).

Tenaculum and ventral tube. Tenaculum with $3+3$ large teeth, basal tubercle produced as $1+1$ well-developed processes (Fig. 6G-H). Ventral tube with $2+2$ apical chaetae, without clear posterior lobe (Fig. 6I).

\section{Ecology and distribution}

The presence of a species of Spinaethorax in Vietnam indicates that this genus has a much larger distribution than thought when it was described. The species is likely to be cave-restricted, in spite of its weak troglomorphic characters (the claws appear thinned in their distal part, but this may be phyletic rather than adaptive), as we never encountered it in the numerous surface samples we examined in this small region of southern Vietnam. Spinaethorax may have been overlooked because of its cave habitat, but also because it could be a rare species inside caves. The presence of the genus was confirmed in two other caves of the Hon Chong karst (one cave yielding a species new to science, the other yielding juveniles of an unidentified species). Many caves sampled in Southeast Asia contained unidentified Megalothorax, but Spinaethorax remains so far restricted to the Hon Chong karst. However, thorough re-examination of cave Neelidae from the region as well as new sampling may change the figure.

\section{General Discussion}

\section{Threat to the biodiversity of Hang Kim Cuong}

A visit to this cave in October 2014 did not allow to retrieve the undescribed species of the genera Ceratophysella, Folsomides, Pronura and Willemia, probably in relation with complete trampling of the whole floor of the cave by visitors, and disappearance of guano patches. S. adamantis sp. nov. was however recovered.

\section{Morphology}

\section{Integument}

The genus Spinaethorax differs from Neelides, Neelus, Acanthoneelidus and Megalothorax in its integumentary characters. The complete absence of integumentary channels is probably unique in Neelipleona (this character was, however, not studied in Zelandothorax) and the absence of dermastra separates it from the genera Neelus and Neelides. The functions of those two characters are unknown. 
Their absence in Spinaethorax (only cave-dwelling species known) and presence in Neelus (both in troglobitic and edaphic species) suggest the subterranean environment does not put a high selective pressure on those characters.
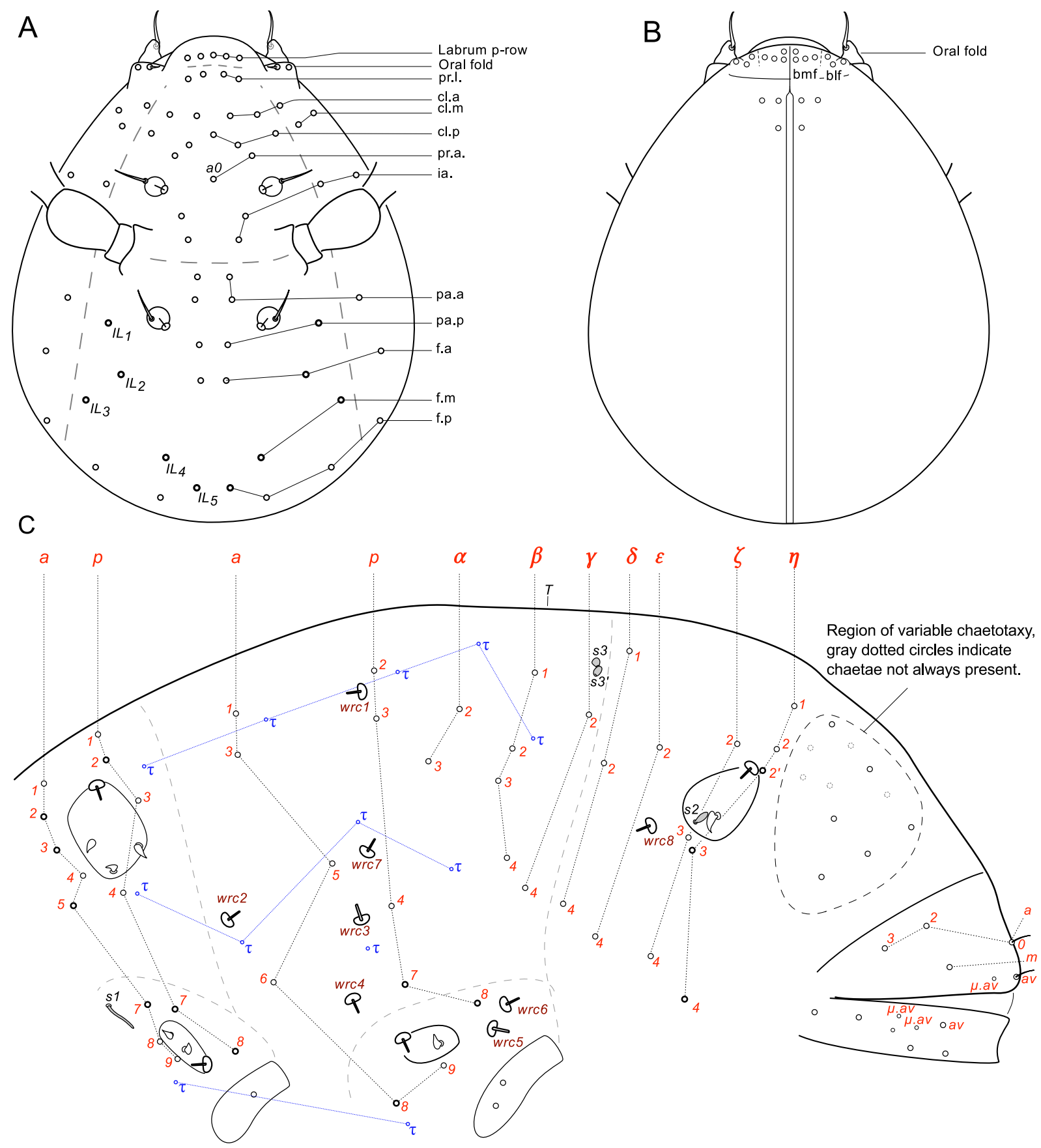

Fig. 7. Spinaethorax adamantis sp. nov. A-B. Diagram of the chaetotaxy of the head: A dorsal side, B ventral side. C. Diagram of the chaetotaxy of the trunk. Enlarged or lanceolate chaetae with thicker line. Nomenclature of chaetotaxy after Schneider \& D'Haese (2013), Schneider et al. (2016) and Schneider (2017), partial equivalence with head nomenclature of S. tonoius (Palacios-Vargas \& Sánchez $1999)$ is given in A (IL 1-5 chaetae). 


\section{Labrum}

One of the most remarkable characters of the genus Neelus and Megalothorax is the highly modified labrum with an anterior process bearing the $\mathrm{m}$ - and a-rows of chaetae (Schneider 2017). This seems also to be the case of the genus Zelandothorax (Delamare Deboutteville \& Massoud 1963; Schneider 2017) while the genera Neelides and Acanthoneelidus have an ordinary labrum. The labrum of Spinaethorax seems to have a somewhat intermediate morphology. The anterior process seems to exist, but is rudimentary (Fig. 9A), with only weak marks of separation from the base of the labrum. The labral ridge is not well contrasted in light microscopy, but appears to be slightly in anterior position relative to the a-row of chaetae (Figs 2C, 9A). The labrum of Spinaethorax is probably related to the labrum of Neelus or Megalothorax, either being an ancestral state or a vestigial state.

\section{Labium}

The labium of Spinaethorax is very similar to the that of of Neelus, with the same chaetotaxic pattern (palp and basal fields). From our observations on S. adamantis sp. nov. we conclude that the chaetotaxy of the basal fields consists of $4+4$ basomedian chaetae and $3+3$ basolateral chaetae. While the $2+2$ most median chaetae of the basolateral fields are much smaller than the $1+1$ lateral chaetae in Neelus murinus sensu Massoud \& Vannier (1967), the $3+3$ chaetae are subequal in $S$. adamantis sp. nov. and S. spinotricosus.

\section{Oral fold}

The presence of a third chaetotaxic element on the oral fold of $S$. adamantis sp. nov. is an unusual character among Collembola. It was not reported for S. tonoius and S. spinotricosus. It is present in at least one other undescribed species of Vietnam and could be an additional characteristic of the genus. The enlargement of the lateral chaeta of the oral fold is present in all material of Spinaethorax examined so far.

\section{Chaetotaxy of the head}

The chaetotaxic diagram in Fig. 7A-B supports a hypothesis of chaeta position homology for S. adamantis sp. nov. and N. folsomi, Neelus murinus, Acanthoneelidus pratensis and several Megalothorax species (discussion in Schneider 2017). The general pattern seems rather similar to that of Neelus murinus. Palacios-Vargas \& Sánchez (1999) introduced a nomenclature for some chaetae of the dorsal, posterior part of the head of S. tonoius, which was used by Papáč \& Palacios-Vargas (2016) for S. spinotricosus. The new species $S$. adamantis sp. nov. has 5 IL-chaetae (Fig. 7A), whereas the Mexican species have fewer. Chaetae IL3 and IL4 of S. spinotricosus (in Papáč \& Palacios-Vargas 2016) are homologized to $I L 4$ and $I L 5$ of $S$. adamantis sp. nov. and S. tonoius lacks IL3. The chaetotaxic pattern of S. spinotricosus is very similar to that of $S$. adamantis sp. nov., but with a few interesting differences: one pair of chaetae missing in the inter-antennal region, likely in the ia.-row, consistent with Neelus murinus. Spinaethorax spinotricosus also has only one axial unpaired chaeta in the anterior, dorsal area, which is unique in Neelipleona both as an absolute character and as an intra-generic variation (Megalothorax, Neelides and Neelus with two axial unpaired chaetae, Acanthoneelidus with three).

\section{Antennae}

The chaetotaxic diagram in Fig. 8 represents a partial hypothesis of chaetal position homology between $S$. adamantis sp. nov. and Neelides folsomi, Neelus murinus, A. pratensis and several species of Megalothorax (discussion in Schneider 2017). The antenna of Spinaethorax is similar to that of Neelus in terms of chaetotaxic pattern. It is distinctive mostly due to the morphology of the S-chaetae of Ant III (S1-S4, Fig. 3A-C), the presence of five modified chaetae on Ant. IV (so far confirmed only in S. adamantis sp. nov., Fig. 3A-B) and the fusion of Ant. III and IV. The morphology of the Ant. IV organite (Fig. 3C) is similar to that observed in the genus Neelus. This peculiar morphology was first reported by Massoud \& Vannier (1967) in Neelus murinus and Neelus labralisetosus. The 
drawings in Massoud \& Vannier (1967, figs 1A, 2A) seem to indicate the presence of a thin membrane between the filaments. Such a membrane does not seem to exist in Neelus koseli Kováč \& Papáč, 2010 (a larger species) (Kováč \& Papáč 2010) and we cannot confirm a membrane in Neelus murinus or S. adamantis sp. nov.

\section{Sensory fields}

The pattern of sensory fields of Spinaethorax is the same as that in Neelus, Megalothorax and Acanthoneelidus. In Spinaethorax, $s f 1$ and $s f 2$ are both devoid of a swollen inner chaeta. Instead, an ordinary chaeta is present on the border of the field. This condition is similar to what is observed in Neelus murinus, for which the $s f 2$ chaeta is hypothesized to be homologous with the $s f 2$ special inner

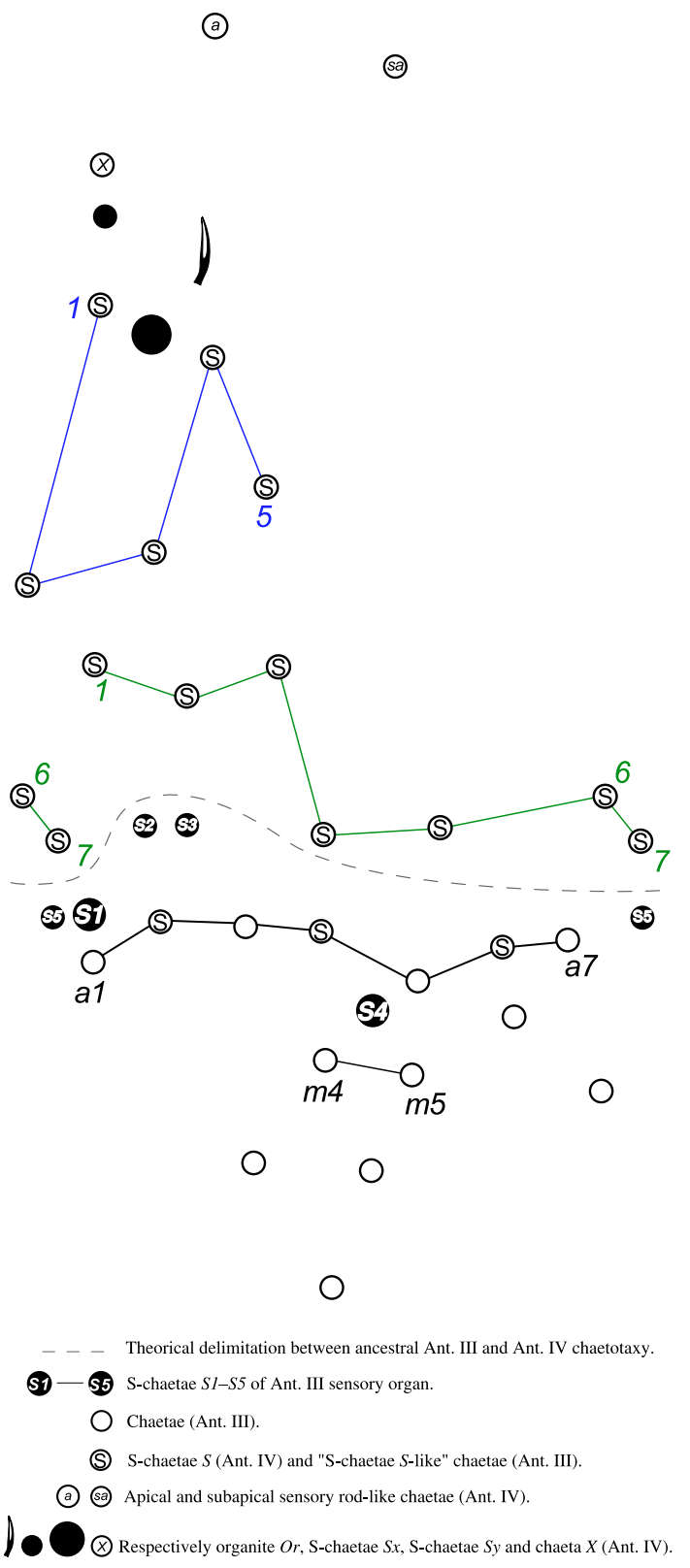

Fig. 8. Spinaethorax adamantis sp. nov., partial diagram of the chaetotaxy of the antenna (Ant. III/Ant. IV). 
chaeta of Megalothorax and Acanthoneelidus (Schneider 2017). Spinaethorax has only one special inner chaeta in $s f 5$, the same state is observed in adults of A. pratensis and juveniles of Neelus murinus and Megalothorax (Schneider 2017). The position of $w r c 8$ and $s 2$ relative to $s f 6$ may be useful at the genus level. In Neelus murinus, $w r c 8$ is in dorsal position and relatively far from $s f 6, w r c 8$ seems directed anterodorsally while $s f 6$ wax secretory element is directed ventrally and $s 2$ is in ventral position (Fig. 9B). In Megalothorax species (except M. granulosus Schneider \& D'Haese, 2013), wrc8 is in anterior position to $s f 6, w r c 8$ seems directed antero-dorsally, $s f 6$ wax secretory element is directed antero-ventrally and $s 2$ is in dorsal position (Fig. 9C). In Spinaethorax, wrc8 is in antero-ventral position to $s f 6$, both $w r c 8$ and $s f 6$ wax secretory elements are, respectively, directed antero-ventrally and ventrally, and $s 2$ is in ventral position (Fig. 9D). In A. pratensis and M. granulosus, wrc 8 is in anterior position to $s f 6$, both wrc 8 and $s f 6$ wax secretory elements seem directed anteriorly or antero-dorsally and $s 2$ is in dorsal position (Fig. 9E-F).

\section{Pseudopore-like elements}

Spinaethorax adamantis sp. nov. lacks the head and trunk pseudopore-like elements reported for Megalothorax (Schneider et al. 2016). However, a pair of similar elements (basal ring without visible chaeta) was observed on the Abd. VI sternum of $S$. adamantis sp. nov. (absent in the other genera).
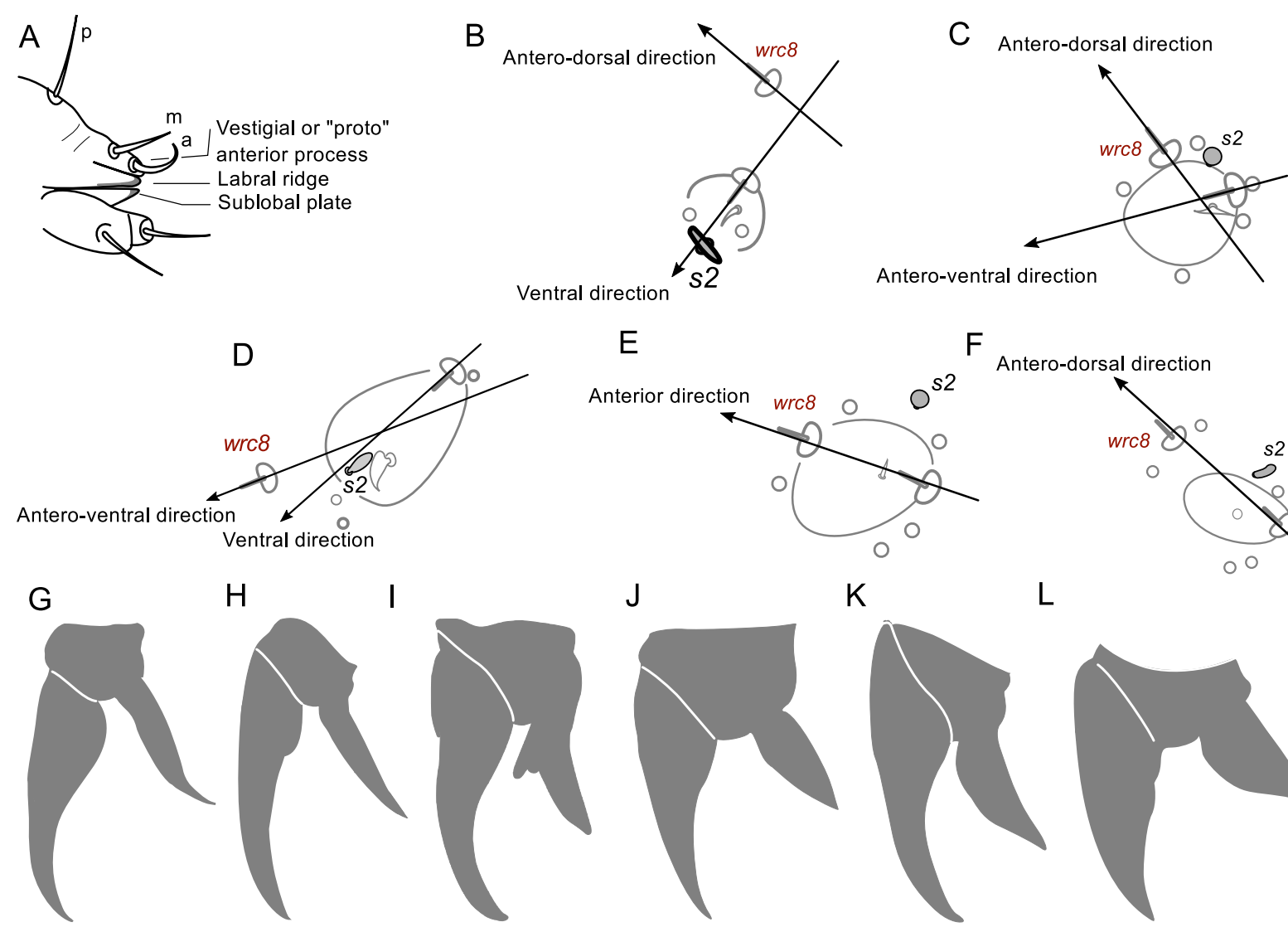

L

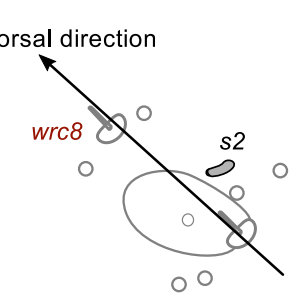

Fig. 9. A. Schematic interpretation of the labrum of Spinaethorax adamantis sp. nov. B-F. Chaetotaxic organization of sf6. B. Neelus murinus. C. Megalothorax minimus. D. Spinaethorax adamantis sp. nov. E. Megalothorax granulosus. F. Acanthoneelidus pratensis. G-L. Outline of claw III, normalized in length, of representatives of the six genera of Neelipleona. G. Spinaethorax adamantis sp. nov. H. Neelus murinus. I. Megalothorax minimus. J. Zelandothorax novaezealandiae. K. Neelides folsomi. L. Acanthoneelidus pratensis. H, I, K, L after Schneider (2017), J after Bonet (1947). 
Wax rod secretory elements

While live observations of wax rods growth have not yet been reported for Spinaethorax, the genus displays the associated wax rod secretory element of sensory fields $(s f 1-s f 6)$ and the free wax rod secretory elements ( $w r c 1-8)$ that are involved with wax rods growth in other Neelipleona. Spinaethorax and Neelus have similar wrc patterns, with $w r c 2$ and $w r c 7$ moved anteriorly from what is observed in Megalothorax and Acanthoneelidus. In S. adamantis sp. nov., wrc 3 and wrc5 have a specially thickened chaetal element. A similar thickening of wrc3 only is observed in Neelus.

An interesting observation is the numerous microspines on abdominal terga of S. spinotricosus. Similar microspines are present in Neelides folsomi (adult) and several representatives of the genus Neelus. It seems to be associated with numerous wax rods growth in live animals and are designated as "tertiary wax rod elements" (Schneider 2017). The microspines of S. spinotricosus might be tertiary wax rod elements. More intriguingly, those microspines are absent in S. adamantis sp. nov. and S. tonoius. The intrageneric variation (presence/absence) of this character is also observed in Neelus (e.g., Neelus murinus and Neelus koseli with microspines, Neelus lackovici Papáč et al., 2016 and Neelus klisurensis Kováč \& Papáč, 2010 without) (Kováč \& Papáč 2010; Papáč et al. 2016; Schneider 2017). In Neelides folsomi, the microspines are completely absent from early instars and are replaced with a reduced number of ordinary chaetae (Schneider 2017). Those observations hint that such a spectacular character, whose function is as yet uncertain, was selected (or dismissed) several times during the evolution of Neelipleona, with underlying heterochronic evolutionary processes.

\section{$\tau$-chaetae}

The pattern of $\tau$-chaetae differs between Neelides $(20+20)$, Neelus and Spinaethorax $(12+12)$, Megalothorax and Acanthoneelidus $(9+9)$. It is an interesting character for Neelipleona systematics at the genus level. The intrageneric stability of the pattern is supported by observations on three species of Neelus (Papáč et al. 2016; Schneider 2017) and eight species of Megalothorax (Schneider \& D’Haese 2013; Schneider et al. 2016; Schneider 2017). The $\tau$-chaetae of S. adamantis sp. nov. are long, similarly to those of Neelus and Megalothorax.

\section{Trunk chaetotaxy}

The chaetotaxic diagram in Fig. 7C represents a partial hypothesis of chaeta position homology between S. adamantis sp. nov. and Neelides folsomi, Neelus murinus, A. pratensis and several Megalothorax species (discussion in Schneider 2017). The number of ordinary chaetae in the posterior region of the great abdomen (Abd. IV, V terga) is greater in S. adamantis sp. nov., S. tonoius, Neelus lackovici and Neelus klisurensis than in other Neelipleona. In S. adamantis sp. nov. the chaetotaxic pattern in this part is variable and prone to asymmetry: on four specimens we observed $6+6,6+6,8+9$ and $10+11$ chaetae in the area indicated in Fig. 7C. We also observed a much greater polychaetosis in an additional specimen of Spinaethorax (undescribed new species, pers. obs.). However, we did not study the region exhaustively and do not propose a chaetal nomenclature for it.

The Abd. VI sternum of the available mature male of $S$. adamantis sp. nov. does not display the special swollen chaetae $(\mathrm{Sm})$ that are a sexual character of male Megalothorax (Schneider \& D'Haese 2013, Schneider et al. 2016) and apparently of male Neelus (Schneider 2017).

\section{Claws}

The morphology of the claws of the species of Spinaethorax is added to the definition of the genus as it is very peculiar. It differs from all other Neelipleona in the following features: lamella la in anterior position (instead of antero-lateral) on claw I; la missing on claw II (instead of present); lamella of the unguiculus apparently conical and with smooth edges reduced, limited to the apex (instead of flattened lamella with smooth edges and possibly bearing anterior and posterior crests). Lamella la can be present 
on claw III (S. spinotricosus) or missing (S. adamantis sp. nov., maybe S. tonoius). Palacios-Vargas \& Sánchez (1999) reported a small tooth on each unguiculus of S. spinotricosus while Papáč \& PalaciosVargas (2016) indicated a small tooth on unguiculus I and none on unguiculus II and III. All unguiculi of S. adamantis sp. nov. are toothless. The general shape of the claw, with basal narrowing, stands out from the other genera (Fig. 9G-L). It remains, nevertheless, more similar to Neelus with a slender unguis and unguiculus. The presence of a well-developed lamella $B p$ is a character shared by Spinaethorax, Neelus, Megalothorax and Zelandothorax.

\section{Furca and tenaculum}

The various characters of the furca and the morphology of the tenaculum of Spinaethorax are similar to what is observed within the genus Neelus. The most noticeable variation is the absence of chaeta $E 3$ on the distal part of dens, also absent in Megalothorax, Zelandothorax, Acanthoneelidus and juveniles of Neelus and Neelides (present in adult).

\section{Conclusion}

The morphological observations indicate a close relationship between Neelus and Spinaethorax. A few characters could, however, raise the alternative hypothesis of a relationship with Megalothorax and Zelandothorax, essentially the fusion of Ant. III/IV, the absence of E3 on dens, the presence of a fine secondary granulation, the absence of dermastra and perhaps the organization of $s f 6$. The comparative morphology of genera of Neelipleona suggests a complex evolutionary history that will need to be investigated in a larger phylogenetic framework than those yet developed (Schneider et al. 2011; Schneider \& D’Haese 2013).

\section{Acknowledgments}

The field trip to southern Vietnam was facilitated by Truong Quang Tam (Institute of Tropical Biology, Ho Chi Minh City) and Prof. Le Cong Kiet (Ho Chi Minh City National University). We deeply appreciated the thorough anonymous reviews, that greatly improved the quality of the manuscript, and we express our thanks to their authors.

\section{References}

Bonet F. 1947. Monografía de la familia Neelidae (Collembola). Revista de la Sociedad Mexicana de Historia Natural 8: 131-192.

Deharveng L., Bedos A., Le C.K., Le C.M. \& Truong Q.T. 2009. Endemic arthropods of the Hon Chong hills (Kien Giang), an unrivaled biodiversity heritage in Southeast Asia. In: Le C.K., Truong Q.T. \& Ly N.S. (eds) Beleaguered Hills: Managing the Biodiversity of the Remaining Karst Hills of Kien Giang, Vietnam: 31-57. Nha Xuat Ban Nong Nghiep, TP. Ho Chi Minh.

Delamare Deboutteville C. \& Massoud Z. 1963. Collemboles Symphypléones. In: Delamare Deboutteville C. \& Rapoport E. (eds) Biologie de l'Amérique Australe. Vol. II: 169-289. Éditions du CNRS. Paris.

Fjellberg A. 1999. The labial palp in Collembola. Zoologischer Anzeiger 237: 309-330.

Kováč L'. \& Papáč V. 2010. Revision of the genus Neelus Folsom, 1896 (Collembola, Neelida) with the description of two new troglobiotic species from Europe. Zootaxa 2663: 36-52.

Laumanns M. (ed). 2011. Karsts and caves of South Vietnam, Part 1: Provinces of Kien Giang, An Giang and Da Nang. Berliner höhlenkundliche Berichte 43: 1-73.

Massoud Z. 1971. Contribution à la connaissance morphologique et systématique des collemboles Neelidae. Revue d'Écologie et de Biologie du Sol 8: 195-198. 
Massoud Z. 1976. Essai de synthèse sur la phylogénie des Collemboles. Revue d'Écologie et de Biologie du Sol 13: 241-252.

Massoud Z. \& Vannier G. 1967. Révision du genre Neelus Folsom 1896 (Collembola) et description de Neelus labralisetosus n. sp. des Îles Salomon. Revue d'Écologie et de Biologie du Sol 4: 625-637.

Palacios-Vargas J.G. \& Sánchez A. 1999. Nuevas especies de Megalothorax (Collembola: Neelidae) de cuevas mexicanas. Folia Entomológica Mexicana 105: 55-64.

Papáč V. \& Kováč L. 2013. Four new troglobiotic species of the genus Megalothorax Willem, 1900 (Collembola: Neelipleona) from the Carpathian Mountains (Slovakia, Romania). Zootaxa 3737: 545575. https://doi.org/10.11646/zootaxa.3737.5.3

Papáč V., Lukić M. \& Kováč L. 2016. Genus Neelus Folsom, 1896 (Hexapoda, Collembola) reveals its diversity in cave habitats: two new species from Croatia. Zootaxa 4088, 51-75. https://doi.org/10.11646/ zootaxa.4088.1.2

Papáč, V. \& Palacios-Vargas J.G. 2016. A new genus of Neelidae (Collembola) from Mexican caves. ZooKeys 569: 37-51. https://doi.org/10.3897/zookeys.569.5984

Schneider C. 2017. Morphological review of the order Neelipleona (Collembola) through the redescription of the type species of Acanthoneelidus, Neelides and Neelus. Zootaxa 4308 (1): 1-94. https://doi.org/10.11646/zootaxa.4308.1.1

Schneider C. \& D'Haese C.A. 2013. Morphological and molecular insights on Megalothorax: the largest Neelipleona genus revisited (Collembola). Invertebrate Systematics 27: 317-364.

Schneider C., Cruaud C., \& D'Haese C.A. 2011. Unexpected diversity in Neelipleona revealed by molecular phylogeny approach (Hexapoda, Collembola). Soil Organisms 83: 383-398.

Schneider C., Porco D. \& Deharveng L. 2016. Two new Megalothorax species of the minimus group (Collembola, Neelidae). ZooKeys 554: 37-68. https://doi.org/10.3897/zookeys.554.6069

Manuscript received: 13 October 2016

Manuscript acepted: 23 January 2017

Published on: 31 October 2017

Topic editor: Gavin Broad

Desk editor: Pepe Fernández

Printed versions of all papers are also deposited in the libraries of the institutes that are members of the EJT consortium: Muséum national d'Histoire naturelle, Paris, France; Botanic Garden Meise, Belgium; Royal Museum for Central Africa, Tervuren, Belgium; Natural History Museum, London, United Kingdom; Royal Belgian Institute of Natural Sciences, Brussels, Belgium; Natural History Museum of Denmark, Copenhagen, Denmark; Naturalis Biodiversity Center, Leiden, the Netherlands; Museo Nacional de Ciencias Naturales-CSIC, Madrid, Spain; Real Jardín Botánico de Madrid CSIC, Spain. 